\title{
Saneamento e qualidade da água de consumo: Comunidade do Segredinho, Amazônia, Pará
}

Objetivou-se avaliar a qualidade da água disponível para consumo, a partir de testes microbiológicos, na comunidade rural do Segredinho, no município de Capanema-PA. Foram realizadas coletas nos poços amazônicos, rede de distribuição e do rio, nos meses de março e outubro de 2019 , analisou-se amostras de água para a detecção de coliformes totais e termotolerantes (Escherichia Coli) a partir de ensaios usando o método $\operatorname{COLItest}^{\oplus}$. Houve diferença entre as campanhas entre o período chuvoso e menos chuvoso, sendo observada uma diminuição no índice de contaminação, no entanto esses resultados poder ser associados aos casos de doenças diarreicas, afetando uma maior porcentagem dos moradores de 7 a 5 anos (26\%). A partir desse estudo, pode-se concluir que as águas utilizadas para consumo, tanto da rede de distribuição, quanto de poços amazônicos, apresentaram contaminação, o que a torna imprópria para o consumo humano conforme a resolução vigente.

Palavras-chave: Saneamento básico rural; Doenças de veiculação hídrica; Microrganismos patogênicos.

\section{Sanitation and quality of drinking water: Segredinho Community, Amazon, Pará}

The objective was to evaluate the quality of the water available for consumption, based on microbiological tests, in the rural community of Segredinho, in the city of Capanema-PA. Collections were carried out in the Amazonian wells, distribution network and river, in the months of March and October 2019, water samples were analyzed for the detection of total and thermotolerant coliforms (Escherichia Coli) from tests using the COLItest ${ }^{\circledR}$ method. There was a difference between the campaigns between the rainy and less rainy periods, with a decrease in the contamination rate, although these results may be associated with cases of diarrheal diseases, affecting a higher percentage of residents aged 7 to 5 years (26\%). From this study, it can be concluded that the waters used for consumption, both from the distribution network, as well as from Amazonian wells, presented contamination, which makes it unsuitable for human consumption, according to the current resolution.

Keywords: Rural basic sanitation; Waterborne diseases; Pathogenic microorganisms.

Topic: Desenvolvimento, Sustentabilidade e Meio Ambiente

Reviewed anonymously in the process of blind peer.
Received: 09/03/2021

Approved: 21/05/2021
Mateus Higo Daves Alves (D)

Universidade Federal Rural da Amazônia,

Brasil

http://lattes.cnpq.br/4912689548545873

http://orcid.org/0000-0001-9369-1338

mateushigo.alves@gmail.com

Gabrielle Costa Monteiro (iD) Universidade Federal Rural da Amazônia,

http://lattes.cnpq.br/8205667465188958 http://orcid.org/0000-0003-4507-1884 monteirogabrielle57@gmail.com

Pedro Moreira de Sousa Junior Universidade Federal Rural da Amazônia, Brasil

http://lattes.cnpq.br/3194428833833524 http://orcid.org/0000-0002-6964-562X pedro.junior@ufra.edu.br

\begin{tabular}{l} 
Luiz Claudio Moreira Melo Junior \\
Universidade Federal Rural da Amazônia, \\
Brasil \\
http://lattes.cnpq.br/3064385690292102 \\
\hline http://orcid.org/0000-0003-3701-9998 \\
\hline luiz.mmelo@hotmail.com \\
Simone de Fátima Pinheiro Pereira \\
Universidade Federal do Pará, Brasil \\
http://lattes.cnpq.br/6059412003152989 \\
simonefp@ufpa.br \\
Antonio Reynaldo de Sousa Costa 10 \\
Universidade Federal de Lavras, Brasil \\
http://lattes.cnpq.br/5860581793460787 \\
http://orcid.org/0000-0001-9883-8423 \\
reynaldosousa69@gmail.com
\end{tabular}

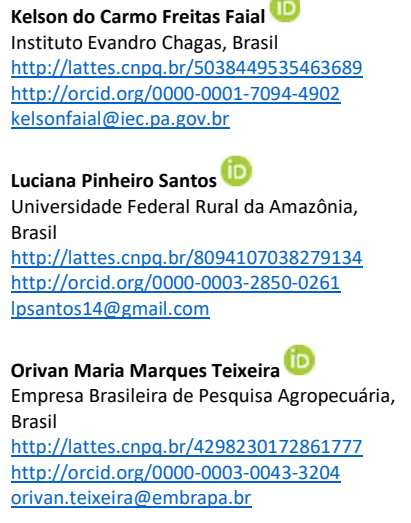

Auriane Consolação da Silva Gonçalves (18) Empresa Brasileira de Pesquisa Agropecuária,

http://lattes.cnpq.br/2109535247435130 http://orcid.org/0000-0001-5722-1777 auriane.goncalves@embrapa.br

Ronaldo Magno Rocha Universidade Federal do Pará, Brasil http://lattes.cnpq.br/5458887479371828 ronaldo.lacen@gmail.com
Referencing this:

ALVES, M. H. D.; MONTEIRO, G. C.; SOUSA JUNIOR, P. M.; MELO JUNIOR, L. C. M.; PEREIRA, S. F. P.; COSTA, A. R. S.; FAIAL, K. C. F.; SANTOS, L. P.; TEIXEIRA, O. M. M.; GONÇALVES, A. C. S.; ROCHA, R. M. Saneamento e qualidade da água de consumo: Comunidade do Segredinho, Amazônia, Pará. Nature and Conservation, v.14, n.2, p.100-110, 2021. DOI: http://doi.org/10.6008/CBPC23182881.2021.002.0010 


\section{INTRODUÇÃO}

A água destinada ao consumo, preparação de alimentos, bebidas e higiene pessoal deve ser livre de patógenos, pois ambientes não sanitizados apresentam diversidade de microrganismos que trazem elevado risco a saúde humana, tornando-se um dos principais fatores responsáveis pela pluralidade de doenças em populações das classes D e E (SILA, 2019). Estudos sobre a qualidade hídrica em aspectos microbiológicos é cada vez mais importante haja vista variedade de microrganismos e a complexidade dos processos analíticos para a determinação dos mesmos (MORAES et al., 2018).

O grupo dos coliformes, são os mais reportados em pesquisas devido a heterogeneidade do gênero e pela fácil infecção, tendo a água como meio de veiculação e contágio. No grupo, há de se destacar a classe dos termotolerantes, que são bactérias indicadoras de contaminação por dejetos humanos ou animais. Geralmente sua infecção está relacionada a ambientes insalubres, como por exemplo, áreas sem rede de esgoto ou com alagamentos constantes (ALMEIDA et al., 2018).

A Escherichia Coli (E. Coli) é um dos indicadores patogênicos de origem fecal mais importantes. Pereira et al. (2019), citam que a presença de bactérias heterotróficas em águas de consumo pode ser responsável por infecções oportunistas em indivíduos com sistema imunológico enfraquecido, além de atuar como reservatórios de plasmídeos de resistência proporcionando interações perigosas com bactérias patogênicas no trato gastrointestinal.

A fim de assegurar que a água destinada ao consumo esteja em conformidade com os padrões estabelecidos pelos órgãos competentes, são promulgadas legislações que regulam teores aceitáveis baseado no seu tipo de uso. Dentre as legislações vigentes que regulamentam a qualidade da água destinada ao abastecimento, destaca-se a Portaria de Consolidação no 05/2017, do Ministério da Saúde, que dispõe sobre os procedimentos de controle e de vigilância da qualidade da água para consumo humano e seu padrão de potabilidade (BRASIL, 2017).

Tais fatores justificam a importância do controle da qualidade da água e exige maior atenção por parte das autoridades sanitárias, como também dos consumidores, sobretudo no que diz respeito à água destinada ao consumo humano (PORCY et al., 2020). Diante do exposto, a pesquisa objetivou avaliar a qualidade da água disponível para consumo, a partir de testes microbiológicos, na comunidade rural do Segredinho, no município de Capanema, estado do Pará.

\section{METODOLOGIA}

\section{Área de Estudo}

A comunidade do Segredinho (Fig. 1), fica localizada na zona rural do município de Capanema, nordeste paraense. Suas principais fontes de abastecimento de água de consumo direto são oriundas de microssistema subterrâneo público e poços amazônicos e de consumo indireto estão o rio do segredo e igarapés que cortam a vila. Segundo informações da concessionária de água, aproximadamente $70 \%$ da vila é atendida pelo microssistema de água implantado na vila. 
Ferreira et al. (2018), caracteriza a dinâmica sócio cultural da população como sendo de subsistência, pautada no cultivo de plantações, criação de animais e pesca como as principais atividades da localidade. Ainda ressaltam sobre os impactos ambientais causados pelo descarte do lixo, desmatamento, além da falta de qualquer infraestrutura sanitária na vila.

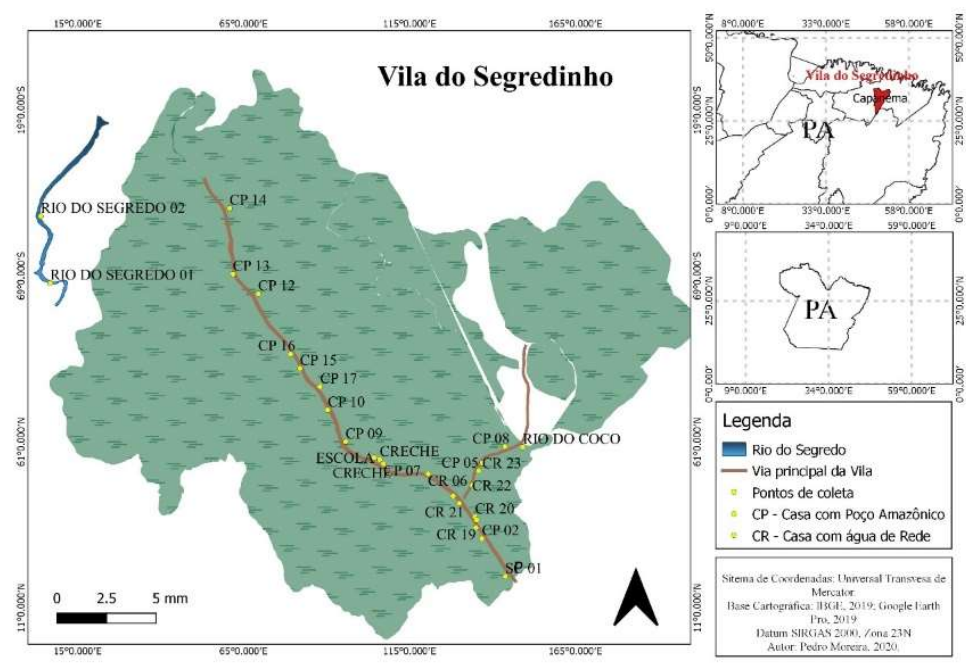

Figura 1: Mapa da localidade, com indicação dos pontos amostrais.

\section{Amostragem e procedimentos de coleta}

A pesquisa foi realizada por meio da coleta de amostras de água da rede de distribuição, poços amazônicos e do rio. A amostragem foi aleatória, contemplando um conjunto de 37 amostras, em triplicata, nos diferentes pontos de coletas, conforme descrito na figura supracitada, representando aproximadamente $50 \%$ dos domicílios da vila.

As coletas foram desenvolvidas em 2 (dois) momentos, nos meses de março e outubro (ambas nos dias 14 e 15) no ano de 2019, com intuito de estabelecer relações entre período chuvoso (janeiro a junho) e pouco chuvoso (julho a dezembro) conforme dados disponibilizados no Instituto Nacional de Meteorologia. Os protocolos utilizados nessa etapa foram baseados no que rege o Manual Prático de Análise de Água da Fundação Nacional de Saúde (2013), além de pesquisas como de Fernandes et al. (2018) e Ferreira Junior et al. (2019) que apresentam objetivos gerais correlatos aos da pesquisa proposta.

Seguindo os protocolos sanitários de higienização e proteção das condições reais das amostras de água a serem analisadas, foi necessário sanitizar previamente as torneiras com algodão embebido em álcool 70\%. Após abertas, deixou-se escorrer a água por aproximadamente 2 minutos, em seguida, foram realizadas coletas em frascos esterilizados e identificados. Processos semelhantes aos adotado por Ferreira Júnior et al. (2019) e Sousa et al. (2019), em suas pesquisas sobre qualidade microbiológica da água.

As amostras de água do rio foram coletadas em frascos estéreis, com tampa e lacre, a uma profundidade de $20 \mathrm{~cm}$ da superfície, procedimento similar ao realizado por Martins et al. (2017) e Silva et al. (2018). Em seguida, todas as amostras foram armazenadas em caixas isotérmicas com temperatura controlada entre 4 a $10^{\circ} \mathrm{C}$ e encaminhadas para análise no laboratório de microbiologia da Universidade 
Federal Rural da Amazônia - Campus Capanema/PA.

\section{Pesquisa domiciliar}

Um questionário de pesquisa foi adaptado e adotado, a partir de revisão literária, com o intuito de coletar informações sobre as condições social, estado de saúde, higiene pessoal, sanitização de alimentos, usos e tratamento da água conforme sugerido por Giné-Garriga et al. (2013). Essa seção foi projetada para reunir informações sobre a ocorrência de diarreia, vômito ou problemas de pele e a causa suspeita. Caso resposta afirmativa, questionava-se a relação com água contaminada, higiene ou tipo de alimentação (ROWLE et al., 2018).

Posterior à pesquisa na vila, foram feitas visitas a Unidade Básica de Saúde (USB) da localidade de Tauarí ao qual é responsável pelo atendimento aos moradores da comunidade do Segredinho. Por meio de oficio, foram solicitados os resultados gerais do ano de 2019 sobre caso de diarreia, vômito, problemas de pele e as faixas etárias, a fim de correlacionar com os resultados da pesquisa microbiológica.

Como o questionário está relacionado aos hábitos de higiene e condição de moradia, essa pesquisa optou em não solicitar dados pessoais para que não entrasse em divergência com o Protocolo de Helsink, embora, todas as entrevistas foram solicitadas a assinatura do Termo de Consentimento Livre e Esclarecido (TCLE), conforme descrito na resolução do Conselho Nacional de Saúde nº 466/2012.

\section{Detalhamento do procedimento experimental}

As bactérias pertencentes ao grupo dos coliformes totais são classificadas como Bacilos Gram Negativos, aeróbicos ou anaeróbios facultativos, não formadores de esporos com capacidade de crescer na presença de sais biliares ou outros compostos ativos de superfície, e que fermentam a lactose com produção de ácidos aldeídos e gás a $35^{\circ} \mathrm{C}$ em 24 a 48 horas. Já os coliformes fecais ou coliformes termotolerantes são bactérias capazes de fermentar a lactose com produção de gás a $44^{\circ} \mathrm{C}$ em 24 horas conforme Martins et al. (2017) e Silva et al. (2018).

Para a análise de coliformes totais e coliformes termotolerantes $(E$. Coli) foi realizado o método proposto pelo fabricante $\mathrm{COLItest}^{\circledast}$. Este apresenta um substrato cromogênico e fluorogênico. A identificação de coliformes totais se dá pela alteração de coloração da amostra. $O$ frasco deve ser mantido 24 horas a temperatura de $35^{\circ} \mathrm{C}$ em uma estufa, para identificação de $E$. Coli (caso a amostra apresente mudança de coloração), utilizando-se uma câmara isolada contendo uma lâmpada UV. A amostra é submetida à radiação, caso haja formação de um anel vermelho, indica presença do patógeno conforme Rowles et al. (2018) e Sousa et al. (2019).

\section{Análise e interpretação dos dados}

A estratégia utilizada para identificação das informações relevantes da pesquisa foi fundamentada em estratégias adotadas por autores Santos et al. (2020) e Nogueira et al. (2018), no qual utilizam técnicas 
de estatística descritiva e análise gráfica para apresentação e interpretação dos resultados. Na confecção dos resultados foi utilizado como ferramenta computacional o software Spss ${ }^{\circledR}$ Statistical 21 , a fim de minimizar os erros sistemáticos e obter resultados mais precisos conforme estudo de Arbos et al. (2017). Os padrões de referência adotados para interpretação dos resultados de Coliformes Totais e Escherichia coli serão pautados na Portaria consolidada no 05/2017 do Ministério da Saúde, além da comparação com autores que desenvolveram pesquisas semelhantes ao objeto desta.

\section{RESULTADOS E DISCUSSÃO}

Os patógenos bacterianos têm grande destaque na veiculação de doenças causadas pela contaminação hídrica, o que justifica o uso de métodos para identificá-los, principalmente, por serem de rápida e fácil identificação (GINÉ-GARRIGA et al., 2013). A viabilidade do método COLltest $^{\circledR}$ possibilita pesquisas nessa área, assim como outros testes que partem de princípio semelhante, como o kit EnZquik, utilizado por Fernandes et al. (2018), e a técnica do número mais provável (SANTOS et al., 2020).

\section{Correlação entre campanha de coleta e resultados microbiológicos}

Os resultados das análises microbiológicas são visualizados na Tabela 1, e nela constatou-se que na primeira campanha $63.2 \%$ das amostras testaram positivo para coliformes totais e $36,8 \%$ do conjunto total testou positivo para Escherichia Coli, enquanto que na segunda campanha houve decréscimo desses valores, $61.1 \%$ estavam contaminadas por coliformes totais e $27.8 \%$ por E. Coli.

Moraes et al. (2018) comentam que durante a captação de água no sistema de abastecimento pode ocorrer contaminação, embora problemas relacionado a condições precárias de tubulação e no reservatório onde está acondicionada não podem ser descartadas.

Tabela 1: Tabulação cruzada entre campanha de coleta e parâmetros microbiológicos.

\begin{tabular}{|c|c|c|c|}
\hline \multirow{2}{*}{ Campanhas } & \multicolumn{2}{|c|}{ Coliformes Totais } & \multirow{2}{*}{ Total } \\
\hline & Positivo & Negativo & \\
\hline 19 coleta & $63,2 \%$ & $36,8 \%$ & $100 \%$ \\
\hline 2o coleta & $61,1 \%$ & $38,9 \%$ & $100 \%$ \\
\hline \multirow{2}{*}{ Campanhas } & Escheri & & \multirow{2}{*}{ Total } \\
\hline & Positivo & Negativo & \\
\hline 10 coleta & $36,8 \%$ & $63,2 \%$ & $100 \%$ \\
\hline 20 coleta & $27,8 \%$ & $72,2 \%$ & $100 \%$ \\
\hline
\end{tabular}

Apesar da diminuição no índice de contaminação, entre as campanhas, estes resultados são considerados insatisfatórios quando confrontados com a portaria no 05/2017 do Ministério da Saúde (MS) que recomenda a ausência deste patógeno em águas destinadas ao consumo humano.

Tal fato alerta que tanto as amostras provenientes do microssistema quanto dos poços amazônicos apresentam-se improprias ao consumo. Essa afirmativa corrobora com as condições encontradas na fonte subterrânea do microssistema, na qual foram identificados pontos de descarte de lixo doméstico, esgoto e fossas negras nas proximidades, além da falta de isolamento protetivo da fonte de captação. 


\section{Correlação entre campanha de coleta, Coliformes Totais e Fonte de consumo}

Os resultados da primeira campanha identificaram alto índice de contaminação nas amostras de água do rio em comparação com as demais fontes de consumo (Figura 2 - A), 100\% das amostras do rio estavam contaminadas por coliformes totais, seguidas dos poços (60\%) e rede de distribuição (20\%).

Os coliformes totais, embora sejam considerados bactérias normalmente encontradas no meio ambiente e possuem poucas cepas patogênicas, indicam biodegradação de matéria orgânica como folhas e restos de animais, ao mesmo tempo que aludem contato direto entre a água e demais constituintes ambientais (ZÚÑIGA, 2015). Na segunda campanha as amostras provenientes do rio não apresentaram contaminação, o que não pode ser atribuído as águas dos poços que continuaram apresentando alto índice de pontos com presença de coliformes totais.

Resultados semelhantes também foram identificados em estudos conduzidos por Ferreira et al. (2017) no qual foram relatados resultados insatisfatórios em relação à qualidade da água em uma comunidade quilombola no Mato Grosso, com 77,78\% de presença de coliformes termotolerantes.

Esses dados referentes aos poços indicam falta ou ineficiência no processo de sanitização dos mesmos, no caso da E. Coli mostra a não ocorrência do tratamento da água, expondo a fragilidade e o risco dos moradores a esse agente patógeno perigoso.

As observações identificadas in loco, apontam para a não ocorrência de uma rede de esgotamento sanitário na vila, condicionando aos moradores a realização de projetos sanitários sem orientação técnica, resultando na escavação de fossas negras próximas aos poços, permitindo processos de infiltração entre fossa e o poço (ZÚÑIGA, 2015).

\section{Correlação entre campanha de coleta, Escherichia Coli e Fonte de consumo}

A figura 2-b ilustra o comparativo entre as campanhas, E. Coli, tipo de fonte e nela foi constatado a não contaminação por E. Coli, nos rios, o qual evidenciou que na segunda campanha, ocorreu a diminuição dos pontos contaminados na rede de abastecimento. Em contrapartida, houve aumento da presença deste patógeno nas águas dos poços.

Norete et al. (2018) comentam que as causas da contaminação de água de poços podem estar associadas à entrada de impurezas por meio do procedimento de abertura do poço, contaminação na ocasião da retirada de água, infiltração de águas de enxurradas de locais próximos ao poço e fossas negras.

Outro fator a ser considerado são os períodos da realização das coletas (chuvoso e menos chuvoso), no qual o período mais chuvoso acarretou em maior contaminação da água dos poços. As ocorrências podem estar associadas a uma possível contaminação dos poços analisados, com a água que percola durante o período de chuva. Verificou-se que o parolamento é o fator de maior contribuição para mudança na qualidade da água subterrânea (NJUGUNA et al., 2020).

Em pesquisa realizada no município de Colinas, no Rio Grande do Sul, sobre a qualidade da água em 
poços, foi evidenciado que $100 \%$ das amostras apresentaram contaminação por coliformes totais e $E$. Coli, resultados que podem ser explicados devido à má conservação destes poços (CASTRO et al., 2020).
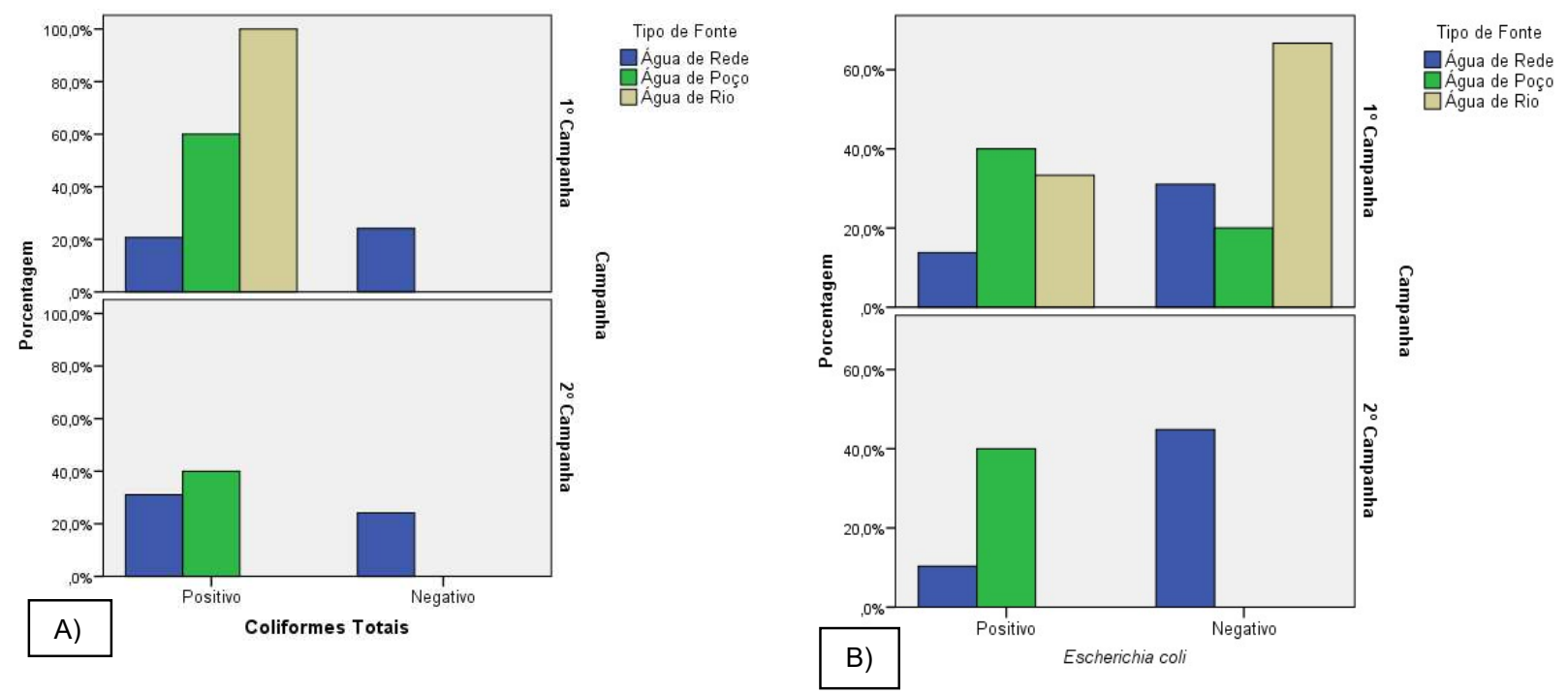

Figura 2: Gráfico comparativo dos resultados entre campanha de coleta: (A) Coliformes Totais e tipo de fonte de consumo.

Estudo semelhante realizado em comunidades ribeirinhas de Itupiranga-PA, observou que existem potenciais fatores de contaminação da água dos poços, que podem ter atuado de forma isolada ou associada, como a falta de condições adequadas de esgotamento sanitário e abastecimento de água, e o descarte de forma inapropriada dos resíduos sólidos, evidenciando riscos à saúde individual e coletiva dos moradores dessas vilas (NOGUEIRA et al., 2018).

O grande percentual de contaminação da água pela presença de coliformes totais e termotolerantes apresentado neste artigo é preocupante, o que pode indicar precárias condições higiênico-sanitárias dos poços da comunidade do Segredinho.

\section{Correlação entre resultados microbiológico, sociocultural e epidemiológico oficial}

No que tange à forma de tratamento da água destinada ao consumo, a comunidade, em geral, não faz uso de muitos métodos para a filtragem da água, sendo que alguns não utilizam nenhum tipo de tratamento ou utilizam apenas um pano na torneira, o mais utilizado quando perguntados é ferver a água, que segundo eles, pode matar tudo o que há na água. Fatores estes que podem contribuir para o elevado índice de coliformes presentes na água e consequentemente ao surgimento de doenças associadas (Figura 3).

No que se refere ao destino dos dejetos domiciliares, parte das residências não possui banheiro no interior das casas ou nas proximidades da residência. Para Ferreira et al. (2017), a destinação inadequada dos resíduos sólidos apresenta grande risco de contaminação por coliformes.

Segundo dados de 2019 (Tabela 2) repassados pelo agente comunitário de saúde da localidade, houve consideráveis percentuais de febre, vômito e diarreia diagnosticados nos moradores. Dentre estes, a maior porcentagem ocorreu entre a faixa etária de 7 a 15 anos com 26\%. Esses elevados índices de doenças 
podem ter associação com a qualidade hídrica e falta de saneamento da localidade.

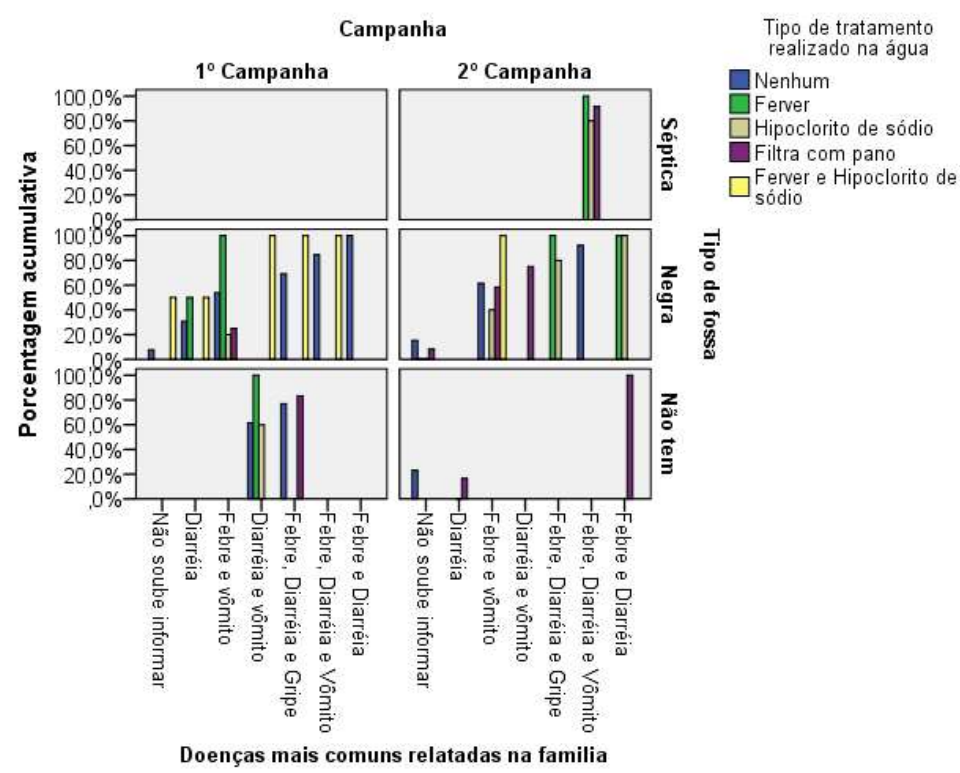

Figura 3: Comparativo dos resultados entre campanha de coleta, Doenças mais comuns relatas e tipo de fossa.

Tabela 2: Resultados do posto de saúde e principais causas.

\begin{tabular}{llll}
\hline Faixa etária & Porcentagem & Diagnóstico médico da UBS & Principais causas \\
\hline $\mathbf{0}$ a $\mathbf{6}$ anos & $23 \%$ & Febre, Diarreia e Vômito & Aguiar et al. \\
$\mathbf{7}$ a $\mathbf{1 5}$ anos & $26 \%$ & Febre, Diarreia e Vômito & Forgiarini et al. \\
$\mathbf{1 6}$ a $\mathbf{3 0}$ anos & $17 \%$ & Manchas de pele & Vieira-Meyer et al. \\
$\mathbf{3 1}$ a $\mathbf{5 0}$ anos & $12 \%$ & Febre, Diarreia e Vômito & Castro et al. \\
Acima de $\mathbf{5 1}$ anos & $22 \%$ & Febre, Diarreia e Vômito & Soares et al. \\
\hline Total de atendidos & $100 \%$ & &
\end{tabular}

* Dados fornecidos pela Unidade Básica de Saúde para as patologias solicitadas (febre, vômito, diarreia e manchas de pele).

Quando não tratada adequadamente, torna-se meio de veiculação de doenças, como gastroenterites (diarreia, vómitos e dor abdominal), cólera, disenteria, febre tifoide, poliomielite e hepatite A. Arbos et al. (2017), comentam ainda que o risco de contrair essas doenças aumenta diante de um quadro de ingestão de água contendo elevada concentração de coliformes.

Castro et al. (2020), fizeram um estudo no Distrito Federal sobre a correlação entre qualidade da água e ocorrência de diarreia e hepatite $\mathrm{A}$, destacando que não só a água de abastecimento é a responsável pela sua transmissão, mas também o esgotamento sanitário e a drenagem também são formas de disseminação dos agentes patogênicos responsáveis por esse agravo de doenças diarreicas e ainda comentam que a ocorrência da hepatite A está intrinsecamente associada à qualidade da água consumida.

Outro fator a ser levantado é os tipos de fossas das residências como também a ausência dela, visto que se trata de uma comunidade com baixa infraestrutura, é normal que algumas residências não tenham banheiro dentro de casa. Ressalta-se, também, que em casas onde não há esgotamento sanitário adequado, há maior tendência à contaminação das águas em áreas sujeitas a inundação (CASTRO et al., 2020).

Forgiarini et al. (2018), realizaram um estudo de análise espacial das doenças diarreicas e identificaram que essas doenças têm uma área de risco, que estão relacionadas com a qualidade dos recursos hídricos e com as características socioeconômicas da população. Os casos de diarreia se aglomeram em 
regiões de maior vulnerabilidade socioeconômica, com residências nas margens do rio que atravessa o município, realidade que se assemelha com a encontrada na comunidade do Segredinho, conforme Figura 4.

Vieira-Meyer et al. (2020), enfatizam em seu trabalho que para a implementação de políticas nacionais voltadas à saúde, se faz necessário apoio adicional às regiões que necessitam de maior incentivo para alcançar melhoria na qualidade de vida. Os índices de doenças relacionadas à contaminação da água na referida localidade, demostra a carência no que se refere ao saneamento.

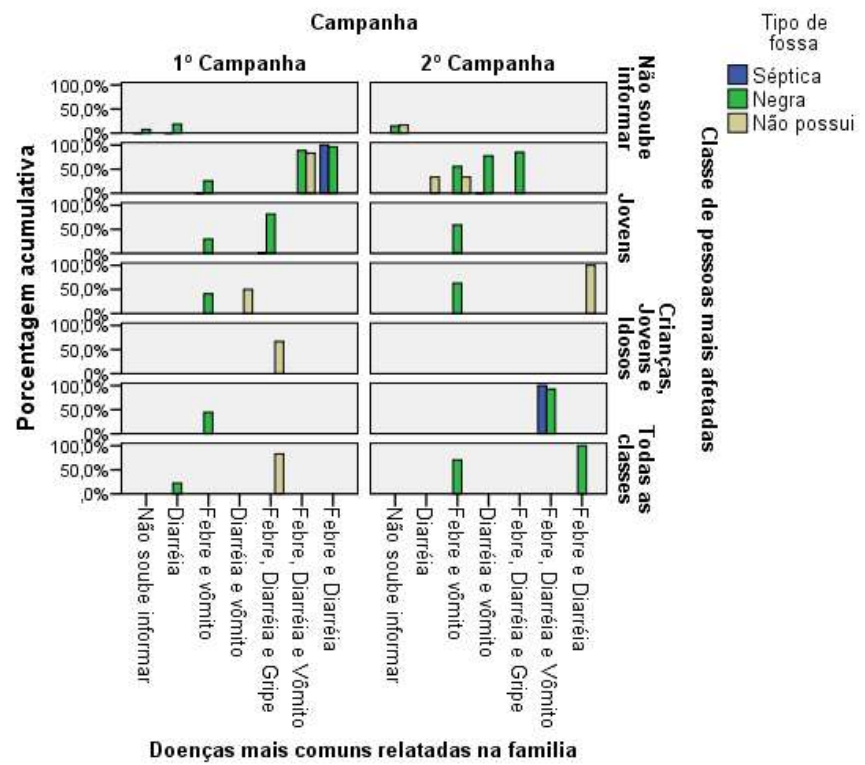

Figura 4: Comparativo dos resultados entre campanha de coleta, Doenças mais comuns relatadas e tipo de fossa.

A presença de banheiro na residência pode ser um fator associado à ocorrência de diarreia, uma vez que as residências que não têm banheiro são desprovidas de saneamento adequado, o que contribui para a contaminação do solo nas adjacências e de lençóis freáticos, que muitas vezes são utilizados como fontes de captação de água para consumo.

\section{CONCLUSÕES}

Os resultados evidenciaram que todas as fontes de água utilizadas para consumo se apresentaram improprias para uso, conforme versa a resolução vigente. Baseado nas análises microbiológicas, do questionário sociocultural e informações da Unidade Básica de Saúde verifica-se a necessidade de uma imediata vigilância, por parte dos órgãos sanitários e de saúde em relação à qualidade microbiológica da água distribuída para a população da comunidade.

A contaminação dos recursos hídricos acarreta em problemas de saúde e os resultados obtidos indicam que os moradores da comunidade podem ter contraído doenças a partir do consumo da água disponível. A pesquisa indica que este cenário está associado à falta de saneamento, más condições dos poços, falta de manutenção na rede de distribuição, fatores que favorecem a propagação de patógenos. 


\section{REFERÊNCIAS}

ALMEIDA, A. N.; CARVALHO, L. R.; ALVES, F. Q.; ADRY, A. P.; SANTINI, A. C.; ALELUIA, M. M.. Análise Microbiológica e físico-química da água de bebedouros em unidades de ensino no município de Ilhéus-BA. Rev. Saúde e Biol., v.12, n.2, p.20-26, 2017.

ARBOS, K. A.; ARAÚJO, I. M.; BORBA, L. O. F.; MELO, L. G. F. O.; SOARES, M. F. S.. Qualidade microbiológica da água para consumo humano no loteamento nova esperança: litoral sul da Paraíba e sua importância para a saúde pública. Rev.

Ciências da Saúde, v.15, n.2, p.50-56, 2017.

BRASIL. Ministério da Saúde. Portaria de consolidação n.5 de 03 de outubro de 2017. Dispõe sobre os procedimentos de controle e de vigilância da qualidade da água para consumo humano e seu padrão de potabilidade. Brasília: MS, 2017.

CASTRO, R. S.; CRUVINEL, V. R. N.; OLIVEIRA, J. L. M.. Correlation between drinking water quality and occurrence of diarrhea and hepatitis A in the Federal District/Brazil. Saúde Debate, v.43, n.3, p.8-19, 2019.

FERNANDES D. B.; CÉSAR, F. G.; MARTINS, A. S.; SANTOS K. J.; VICENTE, E. G.; SANTOS, J. R. E.; SIMÃO, D. A.; CASTELUBER, M. C. F.. Avaliação da qualidade microbiológica da água do córrego Barreirinho no município de Ibirité-MG. Uma comparação com o Kit Enzquik. Rev. Águas Subterrâneas, v.32, n.2, p.275-282, 2018.

FERREIRA JUNIOR, R. L.; PEREIRA, J. B.. Análise microbiológica da água de diferentes fontes da Escola Estadual Agrotécnica Afonso Queiroz. PUBVET, v.13, p.176, 2019.

FERREIRA, F. S.; QUEIROZ, T. M.; SILVA, T. V.; ANDRADE, A. C. O.. À margem do rio e da sociedade: a qualidade da água em uma comunidade quilombola no estado de Mato Grosso. Saúde e Sociedade, v.26, p.822-828, 2017.

FERREIRA, R. R.; SILVA, N. S.; SOUZA, I. V. I.; MELO JUNIOR, L. C. M.. Hábitos alimentares de crianças do $5^{\circ}$ e $6^{\circ}$ ano de uma escola municipal na comunidade rural do Segredinho, município de Capanema, Nordeste Paraense. Caderno de Agroecologia, v.13, n.2, 2018.

FORGIARINI, F. R.; PACHALY, R. L.; FAVARETTO, J.. Spatial analysis of diarrheal diseases and its relationship with the environmental monitoring. Engenharia Sanitária e Ambiental, v.23, v.5, p.963-972, 2018.

FUNASA. Fundação Nacional de Saúde. Manual Prático de Análise de Água. 4 ed. Brasília: FUNASA, 2013.

GINÉ-GARRIGA, R.; PALENCIA, A. J. F.; PÉREZ-FOGUET, A.. Water-sanititation-hygiene mapping: An improved approach for data collection at local level. Science of the Total Environment, v.463/464, p.700-711, 2013.

MARTINS, G. L. A.; COSTA, A. S. V.; BARROS, A. R.; RAMALHO, F. M. G.. Qualidade da água do rio Setúbal em Jenipapo de Minas - MG após construção de barragem. Rev. Ambiente e Água, v.12, n.6, 2017.
MORAES, M. S.; MOREIRA, D. A. S.; SANTOS, J. T. L. A.; OLIVEIRA, A. P.; SALGADO, R. L.. Avaliação microbiológica de fontes de água de escolas públicas e privadas da cidade de Santa Rita (PB). Eng. Sanit. Ambient., v.23, n.3, p.431-435, 2018.

NJUGUNA, S.; ONYANGO, J. A.; GITHAUGA, K B.; GITURU, R. W.; YAN, X.. Application of multivariate statistical analysis and water quality index in health risk assessment by domestic use of river water. Case study of Tana River in Kenya. Process Safety and Environmental Protection, v.133, p.149-158, 2019.

NOGUEIRA, E. F. R.; SILVA, A. R. L.; MIRANDA JUNIOR, R. N. C.; MOURA, L. B. D.; CAVALCANTE, L. G. C.; LEITÃO, J. M. S. R.; FERREIRA, V. S.; SANTOS, A. S.; SILVA, B. M.; CARVALHO, C. I. M.; SOUSA, S. B. G.. Análise comparativa da qualidade da água disponível para consumo nos bebedouros de escolas públicas do município de Santo Inácio do Piauí. REAS, v.14, p.1742-1746, 2018.

NORETE, D. N.; CORREIA, Q. B.; JOSÉ, J. F. B. S.. Qualidade da água utilizada em quiosques de praia. Ambiente Água, v.13, n.2, e2003, 2018.

Pereira AG, Orlando FM, Mourão CC. Avaliação da qualidade microbiológica e georreferenciamento de fontes hídricas utilizadas por moradores do município de Divinópolis (MG). Natural Resources, v.9, n.1, p.11-19, 2019.

PORCY, C.; COSTA, T. S.; NASCIMENTO, V. H. P. C.; MONTEIRO, V. S.; NOGUEIRA, J. N.; MENEZES, R. A. O.. Microbiological evaluation of drinking water of houses located in a flooded area in the municipality of Amapá. REAS/EJCH, v.12, n.4, 2020.

ROWLES, L. S.; ALCALDE, R.; BOGOLASKY, F.; KUM, S.; DIAZARRIAGA, F. A.; AYRES, C.; MIKELONIS, A. M.; TOLEDOFLORES, L. J.; ALONSO-GUITIÉRREZ, M. G.; PÉREZ-FLORES, M. E.; LAWLER, D.; WARD, P. M.; CRUZ-LOPEZ, J. Y.; SALEH, N. $B$.. Perceived versus actual water quality: Community studies in rural Oaxaca, Mexico. Science of The Environment, v.622/623, p.626-634, 2018.

SANTOS, T. L.; CUNHA, C. V.; CAMPOS, A. C. V.; SANTOS, S. C.. Qualidade microbiológica da água para consumo humano em comunidades ribeirinhas de Itupiranga-PA, Brasil. Brazilian Journal of Health Review, v.3, n.4, p.9005-9020, 2020.

SILA, O. N.. Physico-chemical and bacteriological quality of water sources in rurais settings, a case study of Kenya, Africa. Scientific African, v.2, 2019.

SILVA, P. S.; CAGNI, G. S.; LIZAMA, M. A. P.; GONÇALVES, J. E.. Avaliação da qualidade de água: concepção hidrossanitária da Bacia do Rio do Campo, Paraná, Brasil. Revista Ibero-Americana de Ciências Ambientais, v.9, n.8, p.26-38, 2018. DOI: http://doi.org/10.6008/CBPC2179$\underline{6858.2018 .008 .0003}$

SOUSA, M. M.; FARIAS, R. C.; CAVALCANTI, M. S.; TRAJANO, G. A.; LIMA, H. S. C.; BATISTA, F. G. A.. Análise microbiológica de água de poços para abastecimento urbano, na cidade de 
Campina Grande-Paraíba. In: CONGRESSO PARAIBANO DE AGROECOLOGIA, 2; EXPOSIÇÃO TECNOLÓGICA, 4. Anais. Pombal: Caderno Verde de Agroecologia e Desenvolvimento Sustentável, 2019.

VIEIRA-MEYER, A. P. G. F.; MORAIS, A. P. P.; GUIMARÃES, J. M. X.; CAMPELO, I. L. B.; VIEIRA, N. F. C.; MACHADO, M. F. A S.; NOGUEIRA, P. S. F.; NUTO, S. A. S.; FREITAS, R. W. J. F..
Infrastructure and work process in primary health care: PMAQ in Ceará. Rev. Saúde Pública, v.54, p.54-62, 2020. DOI: https://doi.org/10.11606/s1518-8787.2020054001878

ZÚÑIGA, O. E. O.. Análisis de la contaminación microbiológica en el río Combeima, município de Ibagué (Tolima, Colombia). Producción+ Limpia, v.10, n.2, 2015

A CBPC - Companhia Brasileira de Produção Científica (CNPJ: 11.221.422/0001-03) detém os direitos materiais desta publicação. Os direitos referem-se à publicação do trabalho em qualquer parte do mundo, incluindo os direitos às renovações, expansões e disseminações da contribuição, bem como outros direitos subsidiários. Todos os trabalhos publicados eletronicamente poderão posteriormente ser publicados em coletâneas impressas sob coordenação da Sustenere Publishing, da Companhia Brasileira de Produção Científica e seus parceiros autorizados. Os (as) autores (as) preservam os direitos autorais, mas não têm permissão para a publicação da contribuição em outro meio, impresso ou digital, em português ou em tradução. 